\title{
Diacylglycerol lipase $\alpha$ knockout mice demonstrate metabolic and behavioral phenotypes similar to those of cannabinoid receptor 1 knockout mice
}

\author{
David R. Powell*, Jason P. Gay, Nathaniel Wilganowski, Deon Doree, \\ Katerina V. Savelieva, Thomas H. Lanthorn, Robert Read, Peter Vogel, Gwenn M. Hansen, \\ Robert Brommage, Zhi-Ming Ding, Urvi Desai, and Brian Zambrowicz \\ Lexicon Pharmaceuticals, Inc., The Woodlands, TX, USA
}

\section{OPEN ACCESS}

Edited by:

Yong Zhu,

East Carolina University, USA

Reviewed by:

Ken Soderstrom,

East Carolina University Brody School of Medicine, USA

Carmelo Quarta,

Helmholtz Zentrum München, Germany

Marc Reitman,

National Institutes of Health, USA

*Correspondence:

David R. Powell,

Lexicon Pharmaceuticals, Inc. 8800 Technology Forest Place, The Woodlands, TX 77381, USA

dpowel/@lexpharma.com

Specialty section: This article was submitted to Experimental Endocrinology, a section of the journal Frontiers in Endocrinology

Received: 16 March 2015 Accepted: 12 May 2015

Published: 02 June 2015

Citation:

Powell DR, Gay JP, Wilganowski N, Doree D, Savelieva KV, Lanthorn $T H$,

Read $R$, Vogel P, Hansen GM,

Brommage R, Ding Z-M, Desai $U$ and Zambrowicz B (2015) Diacylglycerol lipase a knockout mice demonstrate metabolic and behavioral phenotypes similar to those of cannabinoid receptor 1 knockout mice. Front. Endocrinol. 6:86. doi: 10.3389/fendo.2015.00086
After creating $>4,650$ knockouts (KOs) of independent mouse genes, we screened them by high-throughput phenotyping and found that cannabinoid receptor 1 (Cnr1) KO mice had the same lean phenotype published by others. We asked if our KOs of DAG lipase $\alpha$ or $\beta$ (Dagla or Daglb), which catalyze biosynthesis of the endocannabinoid (EC) 2-arachidonoylglycerol (2-AG), or Napepld, which catalyzes biosynthesis of the EC anandamide, shared the lean phenotype of Cnr1 KO mice. We found that Dagla KO mice, but not Daglb or Napepld KO mice, were among the leanest of 3651 chow-fed KO lines screened. In confirmatory studies, chow- or high fat diet-fed Dagla and Cnr1 KO mice were leaner than wild-type (WT) littermates; when data from multiple cohorts of adult mice were combined, body fat was 47 and 45\% lower in Dagla and Cnr1 KO mice, respectively, relative to WT values. By contrast, neither Daglb nor Napepld KO mice were lean. Weanling Dagla KO mice ate less than WT mice and had body weight (BW) similar to pair-fed WT mice, and adult Dagla $\mathrm{KO}$ mice had normal activity and $\mathrm{VO}_{2}$ levels, similar to $\mathrm{Cnr} 1 \mathrm{KO}$ mice. Our Dagla and Cnr1 KO mice also had low fasting insulin, triglyceride, and total cholesterol levels, and after glucose challenge had normal glucose but very low insulin levels. Dagla and Cnr1 KO mice also showed similar responses to a battery of behavioral tests. These data suggest: (1) the lean phenotype of young Dagla and Cnr1 KO mice is mainly due to hypophagia; (2) in pathways where ECs signal through $\mathrm{Cnr} 1$ to regulate food intake and other metabolic and behavioral phenotypes observed in Cnr1 KO mice, Dagla alone provides the 2-AG that serves as the EC signal; and (3) small molecule Dagla inhibitors with a pharmacokinetic profile similar to that of $\mathrm{Cnr} 1$ inverse agonists are likely to mirror the ability of these Cnr1 inverse agonists to lower BW and improve glycemic control in obese patients with type 2 diabetes, but may also induce undesirable neuropsychiatric side-effects.

\footnotetext{
Keywords: mouse knockout models, diacylglycerol lipase gene, cannabinoid receptor 1 gene, obesity,
} endocannabinoids, 2-arachidonoylglycerol, anxiety, depression

\section{Introduction}

There are an estimated 500 million obese people worldwide (1). This obesity epidemic is a major contributor to the dramatic increase in prevalence of type-2 diabetes (T2D) and the rise in diabetes complications (2). Unfortunately, efforts to induce weight loss by encouraging changes in dietary intake 
and physical activity alone have not reversed the obesity epidemic; this suggests that combining these behavioral modifications with a safe and effective anti-obesity drug regimen is the approach most likely to result in meaningful and sustained loss of body fat (3). Although three new anti-obesity drugs were recently approved in the United States, each has significant safety issues that are being evaluated in post-marketing studies (3). There is a need for additional anti-obesity drugs to complement and/or replace those that are currently approved.

The endocannabinoid (EC) system has long been linked to the regulation of food intake and energy balance (4). The primary psychoactive cannabinoid, $\Delta^{9}$-tetrahydrocannabinol (THC), signals through the G-protein-coupled receptors Cnr1 and Cnr2, also known as CB1 and CB2, respectively (5). The two major endogenous ligands or ECs that signal through these receptors are 2-arachidonoylglycerol (2-AG) and $N$-arachidonoylethanolamine (AEA or anandamide). The final enzymatic step in the synthesis of 2-AG is catalyzed by either diacylglycerol lipase $\alpha$ or $\beta$ (Dagla or Daglb); by contrast, a number of enzymes, including $N$-acylphosphatidylethanolamine-hydrolyzing phospholipase D (Napepld), catalyze the final step in the synthesis of AEA (6-9). Cnr1 is highly and widely expressed in central nervous system (CNS) neurons, including neurons that regulate energy balance, and is also expressed in peripheral organs important for metabolic control; by contrast, Cnr2 is expressed primarily by cells involved in regulating immune function (10). Dagla is much more highly expressed in CNS neurons than in peripheral tissues with CNS expression mirroring that of Cnr1, Daglb is widely expressed but with much lower CNS expression than Dagla, and Napepld is widely expressed with highest expression in the CNS $(6,11)$. In the CNS, Dagla and Daglb demonstrate dendritic expression, consistent with the model that ECs, and particularly 2-AG, produced by post-synaptic cells inhibit presynaptic release of excitatory or inhibitory neurotransmitters by signaling through Cnr1 on presynaptic terminals $(6,12)$.

Food intake can be stimulated by oral delivery of THC, and by injections of either 2-AG or AEA, and this effect is blocked by the Cnr1 inverse agonist rimonabant (13-16). Further evidence that Cnrl mediates this feeding response is provided by studies showing that hypophagia and decreased body weight (BW) are found in Cnr1 knockout (KO) mice and in mice chronically treated with rimonabant $(13,17-21)$. Long-term rimonabant treatment induced weight loss not only in rodent models but also in obese humans studied in multiple clinical trials (22-24). Unfortunately, neuropsychiatric side-effects, which were likely on-target considering the role of ECs in neural pathways regulating a wide range of emotional behaviors, ultimately led to withdrawal of rimonabant from the market (24-26).

In an effort to identify potential drug targets, Lexicon Pharmaceuticals performed a high-throughput phenotypic screen on $>4,650 \mathrm{KOs}$ of independent genes encoding druggable proteins (27-31). As part of this phenotypic screen, body fat was measured in cohorts of chow-fed mice from 3,651 KO lines. Among KO lines identified with potential body fat phenotypes, Cnr1 KO mice had a lean phenotype, confirmed using additional cohorts of mice (30), that was consistent with the lean phenotype of Cnr1 KO mice reported by others $(17,20)$. Although Dagla, Daglb, and
Napepld KO lines have been generated $(9,32,33)$, their body fat levels have not been reported. Because these three proteins are potentially druggable enzymes, Dagla, Daglb, and Napepld KO lines were phenotyped in our screen. We chose to review the screen results for body fat from these $\mathrm{KO}$ lines to determine if any or all shared the lean phenotype of Cnr1 KO mice, and if so to examine them in greater detail to determine how closely other phenotypic characteristics mirrored those of Cnr1 KO mice, including behavioral phenotypes that suggest the possibility of ontarget neuropsychiatric side-effects which would likely preclude developing inhibitors of these enzymes as anti-obesity drugs for humans.

\section{Materials and Methods}

\section{Generation of KO Mice}

ApoE KO mice were obtained from Taconic (catalog no. APOE-M, Taconic Biosciences, Hudson, NY, USA). All other KO mice were generated at Lexicon Pharmaceuticals on a 129 S5/SvEvBrd $\mathrm{x}$ C57BL/6-Tyr ${ }^{\text {-Brd }}$ hybrid background. Our approach to knocking out and phenotyping mouse orthologs of the potentially druggable genes in the human genome is published (27-31). Cnr1 KO, Dagla KO, Daglb KO, and Dagla/Daglb double KO (dagla/b DKO) mice have been described $(30,33)$. Mice heterozygous for both Dagla and $A p o E$ were bred to generate Dagla/ApoE DKO mice. Napepld $\mathrm{KO}$ mice were generated by gene trapping; methods for gene trapping in embryonic stem cells, identifying trapped genes using OmniBank Sequence Tags, characterizing retroviral gene-trap vector insertion sites, and RT-PCR analysis of KO and wild-type (WT) transcripts are published (34). Briefly, a retroviral gene-trap vector was used to produce OmniBank clone OST429065, which contains an intron 3 insertion that truncates the Napepld gene product immediately after the second coding exon; this clone was used to generate Napepld KO mice (Figure S1 in Supplementary Material). Genotyping was performed on tail DNA as described previously (34).

\section{Mouse Care and Study}

All studies were performed in strict accordance with the recommendations in the Guide for the Care and Use of Laboratory Animals of the National Institutes of Health. The protocols for all studies were approved by the Lexicon Institutional Animal Care and Use Committee (OLAW Assurance Number, A415201; AAALAC International Accreditation Number, 001025). General methods for mouse care have been described (34). Mice were fed either standard rodent chow $(3.56 \mathrm{kcal} / \mathrm{g}$; $9 \mathrm{~F}$ 5020, Purina, St Louis, MO, USA), low-fat diet (LFD) containing $10 \% \mathrm{kcal}$ from fat $(3.85 \mathrm{kcal} / \mathrm{g}$; D12450B, Research Diets, New Brunswick, NJ, USA), high-fat diet (HFD) containing 45\% $\mathrm{kcal}$ from fat $(4.73 \mathrm{kcal} / \mathrm{g}$; D12451, Research Diets), or western diet (4.7 kcal/g; D12079B; Research Diets). Pair-feeding and food consumption studies were performed as described previously (35).

\section{Body Composition Determinations}

Body composition was measured using either dual energy $\mathrm{x}$-ray absorptiometry (DEXA; PIXImus, InsideOutside Sales, Fitchburg, 
WI, USA) or quantitative magnetic resonance (QMR, ECHO Medical Systems, Houston, TX, USA) technologies as described previously (30). For our phenotypic screen, body fat was analyzed on 14-week-old mice by DEXA and data presented as described previously (30). Briefly, for each KO line, mean KO \% body fat/ mean WT littermate \% body fat was calculated for both male and female mice, and then these male and female values were averaged, yielding a normalized \% body fat value. For most KO lines, four male $\mathrm{KO}$, two male $\mathrm{WT}$, four female $\mathrm{KO}$, and two female WT mice were analyzed. Lines with fewer than four KO mice or fewer than three WT mice were excluded. For lines with uneven distributions of male and female mice, values for the normalized \% body fat calculation were weighted to take into account the actual number of mice analyzed. For X-linked lines, only male data were used.

\section{Stool Analysis}

Group-housed KO and WT mice were fed HFD containing green dye to aid in stool identification. Each cage of mice underwent 24-h stool collections for three consecutive days. After each $24-\mathrm{h}$ stool collection was weighed, lipids were extracted over $24 \mathrm{~h}$ using distilled acetone in a Soxhlet apparatus. After removal of residual acetone by evaporation, each stool collection was reweighed, with the difference in weights representing the amount of acetoneextractable fat.

\section{Measurements of Physical Activity and $\mathrm{VO}_{2}$}

Mice were individually placed in Oxymax chambers (Oxymax, Columbus Instruments, Columbus, OH, USA) and allowed to acclimate overnight. Starting at 10:00 a.m. the following day, each mouse had $\mathrm{VO}_{2}$ and physical activity measured over the next $24 \mathrm{~h}$ as described previously (35). Mice were also studied in a second system that measures physical activity, the ER-4000 physiological measurement system (Mini Mitter, Bend, OR, USA). In these studies, mice first had E-mitter transponders surgically implanted into their peritoneal cavity; after a 3-day recovery period, mice were placed in individual cages within range of an ER-4000 receiver, which measures activity by sensing the strength of the signal received from the E-mitter. Activity data for each mouse were collected in 10 min intervals, and averaged per hour, for a period of 3 weeks using the VitalView Data Acquisition System (Mini Mitter).

\section{Blood Sample Analysis}

Unless stated otherwise, blood was obtained from fed mice by retro-orbital bleed and serum was assayed for glucose, total cholesterol, total triglycerides (TGs), alanine aminotransferase (ALT), and aspartate aminotransferase (AST) by Cobas Integra 400 analyzer (Roche Diagnostics, Indianapolis, IN, USA) as described previously (34).

\section{Oral Glucose Tolerance Tests}

Oral glucose tolerance tests (OGTTs) were performed on conscious, unanesthetized mice. After an overnight fast, mice were bled from the retro-orbital plexus at baseline and then received $2 \mathrm{~g} / \mathrm{kg}$ glucose by oral gavage. Whole-blood samples obtained from the retro-orbital plexus at 0,30 , and 60 min were directly assayed for glucose levels by ACCU-CHEK Aviva glucometer (Roche, Indianapolis, IN, USA); serum obtained at 0 and $30 \mathrm{~min}$ was used to measure insulin levels (Ultra Sensitive Rat Insulin ELISA Kit, Cat. 90060; Crystal Chem, Downers Grove, IL, USA).

\section{Pathology}

Livers obtained from 20- to 24-week-old WT, Dagla KO, ApoE KO, and Dagla/ApoE DKO littermate mice fed western diet since weaning were prepared for histopathologic examination as described previously (35). Liver sections were interspersed during reading by a pathologist to reduce bias, and were given semi quantitative scores of $0-4$, without knowledge of genotype, for degree and extent of fatty cytoplasmic vacuolation (steatosis) and for number and extent of small histiocytic and mixed inflammatory foci replacing hepatic parenchyma (inflammation) (36).

\section{Behavioral Testing}

Dagla and Cnr1 KO mice were studied in tail suspension and forced swim tests developed to screen antidepressant compounds (37), open field and platform tests developed to screen anxiolytic compounds (38), the hot plate test used to assess nociceptive pain (39), and the marble burying test used to screen compounds for possible effects on anxiety, depression, and the repetitive behavior of obsessive compulsive disorder (40). Our protocols for tail suspension, forced swim, open field, marble burying, and hot plate tests are published (41), as is our protocol for the platform test (38).

\section{Statistics}

Data are presented as mean \pm SD. Unless stated otherwise, comparisons between two groups were analyzed by unpaired Student's $t$-test, and comparisons among three or more groups were analyzed by one-way ANOVA, with post hoc analysis performed using the Bonferroni correction. For all behavioral tests, for body fat analysis from the Dagla/b DKO study, and for liver histopathology and body composition analyses from the Dagla/ApoE DKO study, two-way ANOVA was employed. All statistical tests were performed using PRISM 4.03 (GraphPad). Differences were considered statistically significant when $P<0.05$.

\section{Results}

Similar to Cnr1 KO mice, Dagla KO mice were lean relative to WT littermates in our high-throughput phenotypic screen of 3,651 KO lines maintained on chow diet; by contrast, neither Daglb nor Napepld KO mice were lean in this screen (Figure 1A). Dagla mice had normal Mendelian distribution at weaning (923 WT, $1882 \mathrm{Het}$, $971 \mathrm{KO}$ ) and appeared healthy, similar to $\mathrm{Cnr} 1$ (378 WT, 717 Het, 318 KO), Daglb (173 WT, 332 Het, 169 KO), and Napepld (77 WT, $150 \mathrm{Het}, 82 \mathrm{KO})$ mice. To confirm the lean phenotype observed during screening, additional cohorts of chow-fed male and female Dagla KO mice were studied and were found to have significantly decreased BW, body fat, and lean body mass (LBM) at weaning and through 20 weeks of age (Figures 1B,C).

Dagla KO mice fed HFD from weaning developed significantly decreased BW, body fat, and LBM relative to WT littermates (Figures 2A,B). When we combined QMR data obtained at 15-17 weeks of age from multiple chow- and HFD-fed cohorts, 

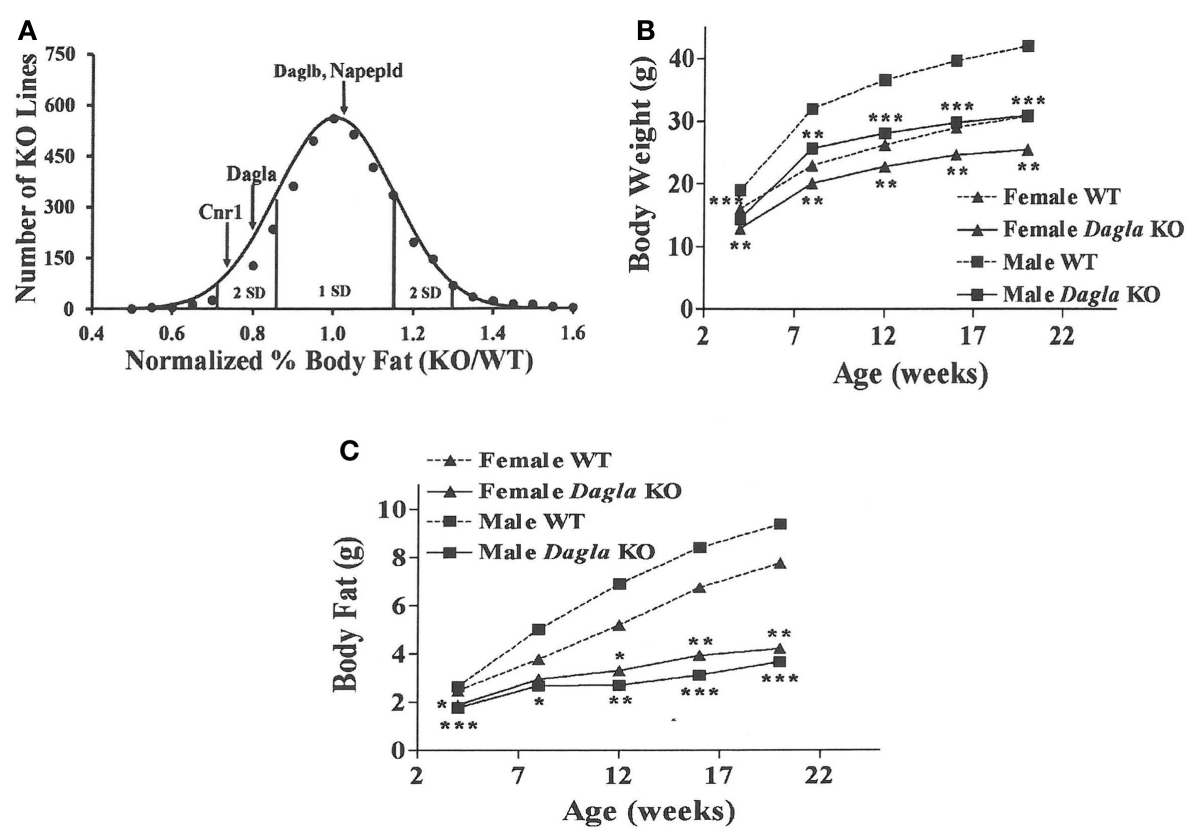

FIGURE 1 | Chow-fed Dagla KO mice are lean. (A) Histogram of normalized\% body fat for 3,651 knockout lines maintained on chow diet. Body composition analyses performed by DEXA on 14-week-old male mice fed chow diet from weaning were used to calculate normalized \% body fat for each knockout line as described in Materials and Methods. The mean normalized $\%$ body fat value was $1.08 \pm 0.15$; the distribution was normal based on Kolmogorov-Smirnov testing $(P<0.01)$. Solid points indicate actual numbers of knockout lines. Curved line shows the calculated curve; the range for 1 and 2 SD from the mean are indicated by lines located below the curve, and values for Cnr1, Dagla, Daglb, and Napepld KO mice are indicated by lines shown above the curve. (B) Time course for body weight of chow-fed Dagla KO mice and their WT littermates. (C) Time course for body fat measured by QMR of chow-fed Dagla KO mice and their WT littermates. For each data point in (B,C), $N=7-15$ mice. $K O$ mice different from WT mice of the same age and gender, ${ }^{\star} P<0.05$, ${ }^{\star \star} P<0.01$, ${ }^{\star \star \star} P<0.001$. we found that BW, body fat, and LBM were significantly decreased by 21,47 , and $11 \%$, respectively, in 131 Dagla KO mice compared to 169 WT littermates (Figures 2C-E; Table S1 in Supplementary Material); because normalized data from male and female $\mathrm{KO}$ mice were comparable, they were combined for this analysis. The lean phenotype persisted with age, and was still present in Dagla KO mice aged more than 1 year (Table 1). The body composition phenotype of Dagla KO mice was confirmed by DEXA analysis (Table S2 in Supplementary Material), which also revealed a slightly decreased bone mass for 29-week-old Dagla KO mice that was probably appropriate for their slightly smaller skeletal frame as demonstrated by femur length measurements (Figure 2F). The lean phenotype of Dagla KO mice is quite similar to that observed in our Cnr1 KO mice (30). In an update of our Cnr1 KO data, we combined QMR measurements obtained at 16-32 weeks of age from multiple chow- and HFD-fed cohorts and found that BW, body fat, and LBM were significantly decreased by 18,45 , and $8 \%$, respectively, in 80 Cnr1 KO mice compared to 102 WT littermates (Figures 3A-C; Table S3 in Supplementary Material); because normalized data from these male and female $\mathrm{KO}$ mice were comparable, they were combined for this analysis. By contrast, neither Napepld nor Daglb KO mice raised on HFD showed decreased body fat at 15 weeks of age (Figures 3D,E). In addition, DAGLa/b DKO mice showed no enhancement of the low body fat phenotype over that observed in DAGLa KO mice (Figure 3F); these mice appeared healthy at weaning, and their Mendelian distribution was normal.

We sought to identify the mechanism behind the low-body fat phenotype of Dagla KO mice. We found that Dagla KO mice ate significantly less than WT littermates at weaning (Figure 4A), similar to Cnr1 KO mice (Figure 4B). A pair-feeding study, performed on female Dagla mice beginning at weaning, showed that pair-fed WT mice had BWs similar to Dagla KO mice and significantly less than WT mice fed ad lib (Figure 4C), suggesting that the lean phenotype of Dagla KO mice at weaning was primarily due to decreased food intake. By contrast, when we studied 27-week-old Dagla KO mice with an established lean phenotype, we found that WT littermates pair-fed to these Dagla KO mice showed an insignificant loss of BW relative to WT littermates that were fed ad lib (Figure 4D). Adult Dagla KO mice did not show evidence of malabsorption (Figures 5A,B) and, in addition, had $\mathrm{VO}_{2}$ (Figure 5C) and total activity (Figure 5D) levels that were not different from those of WT littermate controls. The total activity data were confirmed using a different technology in a separate cohort (Figure 5E). Similar to Dagla KO mice, Cnr1 KO mice had total activity levels that were comparable to levels of WT littermates (Figure 5F).

We evaluated the effect of Dagla deficiency on metabolic parameters. Although Dagla KO mice maintained on HFD had fasting blood glucose levels that were not different from WT, and responded to an OGTT with only modest lowering of glucose 


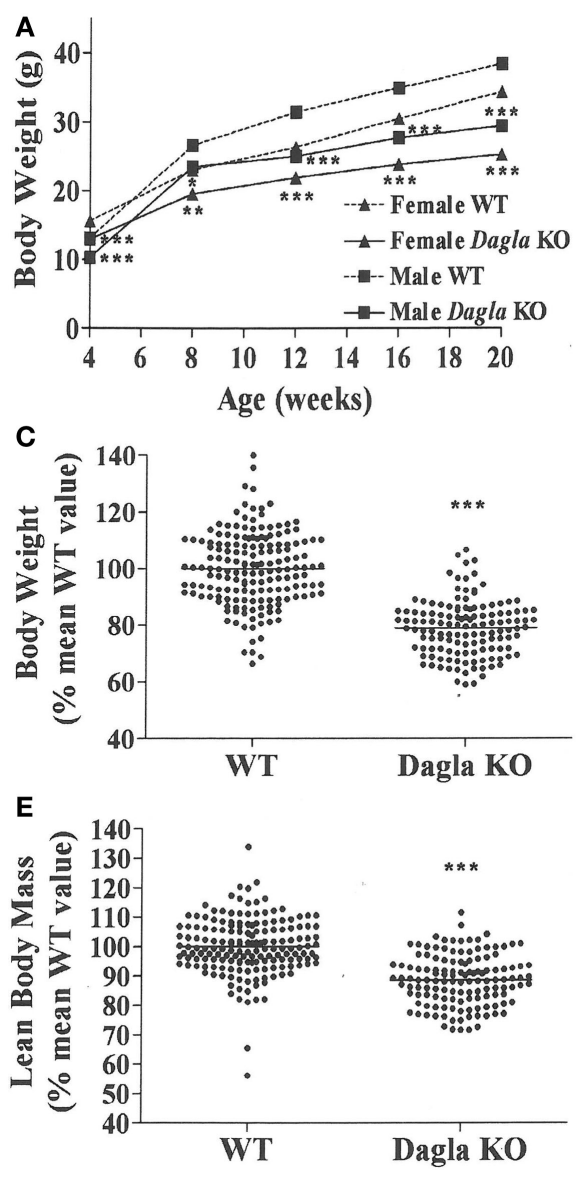

FIGURE 2 | Dagla KO mice are lean on various diets. (A) Time course for body weight of Dagla KO mice and their WT littermates fed HFD. (B) Time course for body fat measured by QMR of Dagla KO mice and their WT littermates fed HFD. For (A,B), $N=12-15$ mice for each data point. Normalized data for (C) body weight, (D) body fat measured by QMR, and
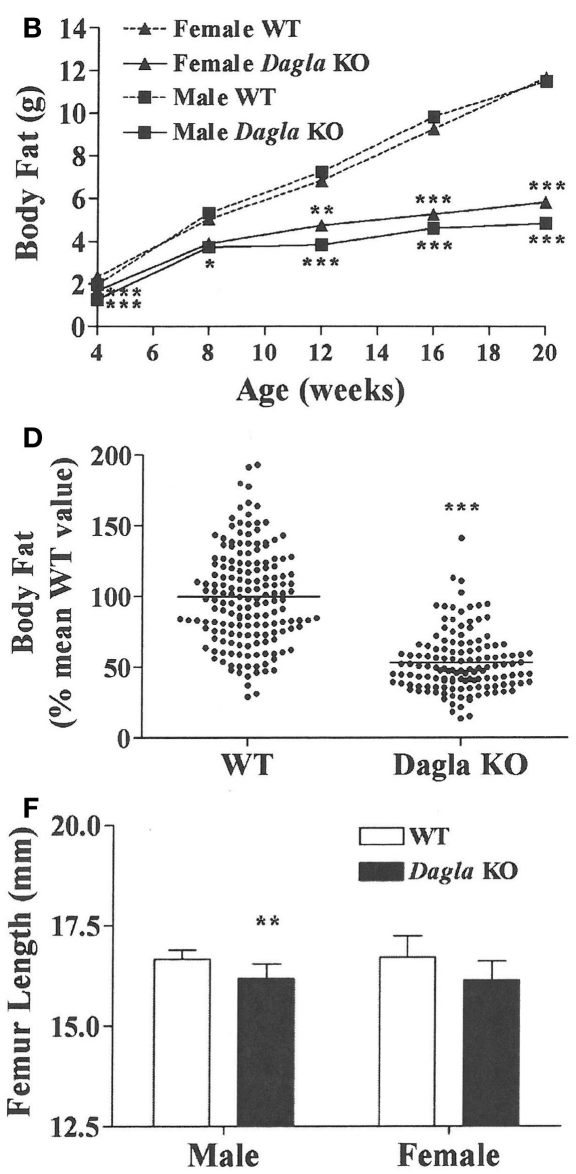

(E) LBM measured by QMR on 16-week-old Dagla KO mice $(N=131)$ and their WT littermates $(N=169)$ fed various diets. $(\mathbf{F})$. Length of femurs from Dagla $\mathrm{KO}$ mice ( $N=8$ males and 6 females) and their $\mathrm{WT}$ littermates ( $N=9$ males and 8 females). KO mice different from WT mice of the same age and gender, ${ }^{\star} P<0.05,{ }^{* \star} P<0.01,{ }^{* \star} P<0.001$.

TABLE 1 | Body composition by QMR of Dagla KO and WT mice at $>1$ year of age.

\begin{tabular}{|c|c|c|c|c|c|c|c|}
\hline Cohort & Genotype & $N$ & Age (months) & Body weight (g) & Body fat (g) & $\%$ Body fat & LBM (g) \\
\hline $2-M$ & WT & 9 & 14 & $55.8 \pm 8.4$ & $19.8 \pm 4.8$ & $35.0 \pm 5.5$ & $36.0 \pm 4.5$ \\
\hline $2-M$ & $\mathrm{KO}$ & 6 & 14 & $41.9 \pm 5.8^{*}$ & $13.1 \pm 6.1^{*}$ & $35.0 \pm 7.3$ & $28.8 \pm 4.2^{\star \star}$ \\
\hline $2-F$ & WT & 6 & 14 & $35.8 \pm 7.7$ & $11.1 \pm 7.4$ & $29.0 \pm 12.9$ & $24.7 \pm 2.6$ \\
\hline $2-F$ & $\mathrm{KO}$ & 7 & 14 & $24.5 \pm 2.1^{\star \star}$ & $3.9 \pm 0.7^{*}$ & $16.0 \pm 1.9^{\star}$ & $20.6 \pm 1.7^{* \star}$ \\
\hline $3-M$ & WF & 10 & 14 & $55.1 \pm 6.5$ & $21.1 \pm 4.5$ & $37.9 \pm 4.1$ & $34.0 \pm 2.5$ \\
\hline $3-M$ & $\mathrm{KO}$ & 8 & 14 & $34.3 \pm 6.9^{\star \star \star}$ & $8.6 \pm 4.6^{\star \star \star \star}$ & $23.7 \pm 8.0^{\star \star \star \star}$ & $25.7 \pm 2.5^{\text {***}}$ \\
\hline $3-F$ & WF & 10 & 15 & $40.5 \pm 9.4$ & $15.4 \pm 7.7$ & $36.3 \pm 9.5$ & $25.1 \pm 2.4$ \\
\hline $3-F$ & $\mathrm{KO}$ & 6 & 15 & $26.3 \pm 4.2^{\star \star}$ & $6.0 \pm 1.3^{\star}$ & $22.9 \pm 2.7^{\star \star}$ & $20.3 \pm 3.2^{\star \star}$ \\
\hline $8-F$ & WT & 7 & 15 & $42.4 \pm 9.3$ & $16.8 \pm 7.4$ & $38.0 \pm 9.7$ & $25.6 \pm 2.3$ \\
\hline $8-F$ & $\mathrm{KO}$ & 7 & 15 & $26.8 \pm 2.9^{\star \star}$ & $5.1 \pm 1.5^{\star \star}$ & $18.7 \pm 3.8^{\star \star \star}$ & $21.7 \pm 1.7^{\star \star}$ \\
\hline
\end{tabular}

Data presented as mean $\pm S D ; N=$ number of mice; $M=$ male; $F=$ female; $L B M$, lean body mass. $K O$ different from $W F,{ }^{*} P<0.05 ;{ }^{* *} P<0.01 ;{ }^{* * *} P<0.001$.

excursions relative to WT values, they did exhibit significantly lower 0 and $30 \mathrm{~min}$ insulin levels (Figures 6A-D); thus, less insulin was required to maintain post-prandial glucose excursions in these non-diabetic mice. Cnr1 KO mice maintained on HFD also showed no difference from WT mice in terms of fasting blood glucose and, during OGTTs, exhibited an insignificant improvement in glucose excursions associated with significantly lower 0 and 30 min insulin levels (Figures 6E,F). Fasting TG and total 

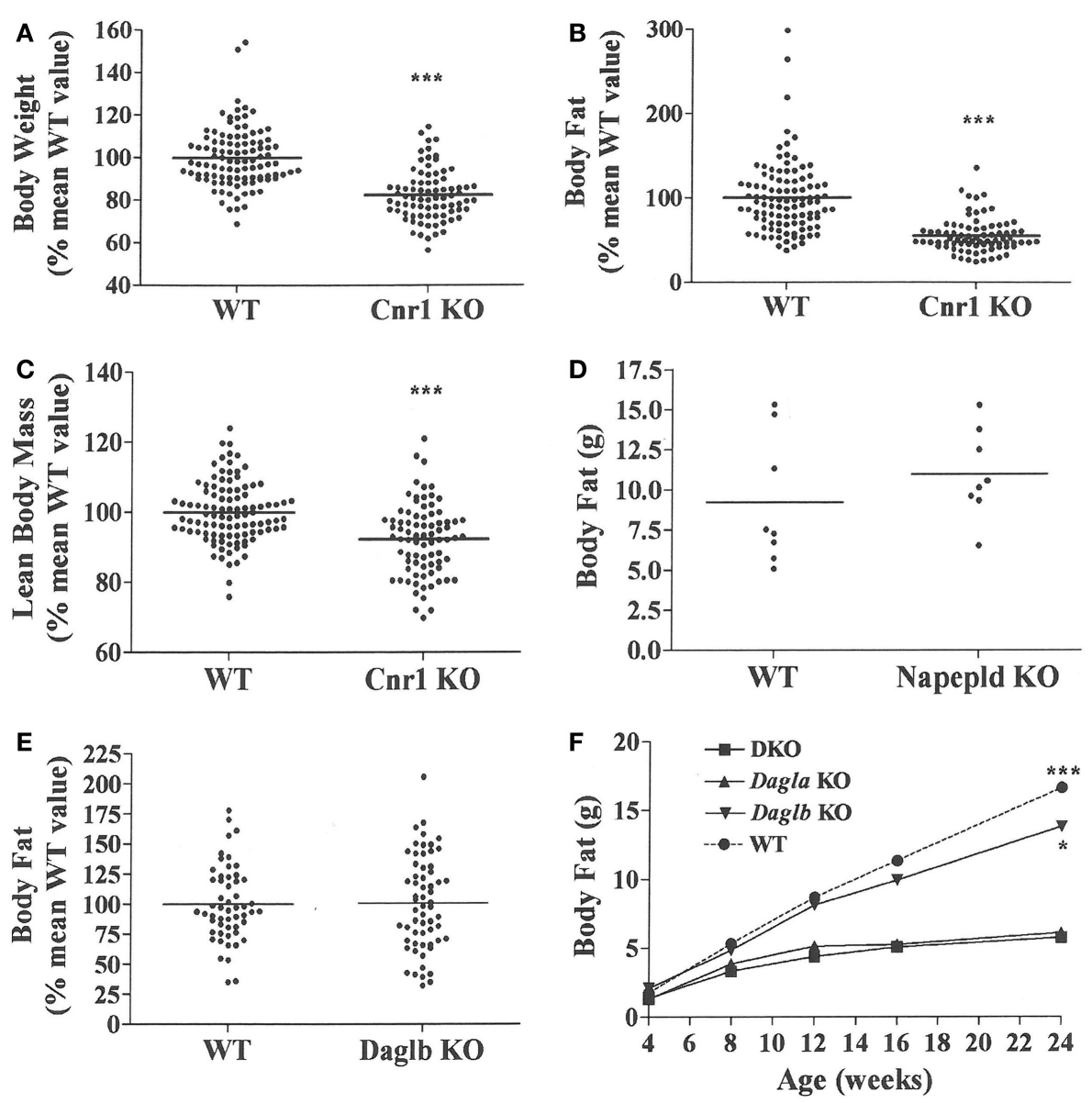

FIGURE 3 | Presence of a lean phenotype in Cnr1 KO mice but not Napepld or Daglb KO mice. Normalized data for (A) body weight, (B) body fat measured by QMR and (C) LBM measured by QMR on 16- to 32-week-old Cnr1 KO mice $(N=80)$ and their WT littermates $(N=102)$. (D) Body fat measured by QMR on 8 male Napepld KO mice and 8 male WT littermates at 12 weeks of age. (E) Normalized body fat measured by QMR on 61 Daglb KO mice and 54 WT littermates at
15-16 weeks of age. For (A-E), KO mice different from WT mice,

${ }^{* \star *} P<0.001$. (F) Time course for body fat measured by QMR on female Dagla KO, Daglb KO, Dagla/b DKO, and WT littermates $(N=6-8$ mice/ group). When analyzed by one-way ANOVA, different from Dagla KO and DKO mice, ${ }^{\star} P<0.05,{ }^{\star \star *} P<0.001$. When analyzed by two-way ANOVA, Dagla KO mice different from WT mice, $P<0.001$; there was no interaction between Dagla KO and Daglb KO on body fat. cholesterol levels tended to be lower in multiple cohorts of Dagla KO mice-fed HFD (Table S4 in Supplementary Material); when data were normalized such that mean WT values for each male and female cohort were assigned a value of $100 \%$, and all data were then combined, TG and total cholesterol levels were significantly lower in Dagla KO mice, measuring 75 and $87 \%$ of WT littermate values, respectively (Figure 6G). Cnr1 KO mice weaned onto HFD showed a similar pattern (Table S4 in Supplementary Material); when data were again normalized and combined, TG and total cholesterol levels were significantly lower in Cnr1 KO mice, measuring 83 and $80 \%$ of WT littermate values, respectively (Figure $6 \mathbf{H}$ ). We also studied whether Dagla deficiency would protect against hepatic steatosis and inflammation by placing Dagla KO mice, ApoE KO mice, Dagla/ApoE DKO mice, and WT littermates on Western diet from weaning (Table 2). When these mice were studied at 20-24 weeks of age, Dagla but not ApoE KO mice were lean relative to WT littermates, and histologic examination of hepatic tissue demonstrated that Dagla deficiency significantly protected WT mice from steatosis but not inflammation, whereas ApoE deficiency had no effect on either parameter in this analysis. Serum analysis showed that ApoE KO mice had increased TG, total cholesterol, and AST relative to WT littermates, and that the addition of Dagla deficiency to ApoE deficiency significantly lowered each of these parameters. Comparable studies were not performed using Cnrl KO mice.

Dagla and Cnr1 KO mice were also evaluated for their performance during a number of behavioral tests (Table 3). During the tail suspension test, neither Dagla nor Cnr1 KO mice showed a significant difference in immobility time relative to WT littermates. The forced swim test showed significantly decreased immobility time in Dagla KO mice, while a much smaller cohort of Cnr1 KO mice showed a strong trend $(P=0.07)$ toward a similar decrease. In the open-field test, neither Dagla nor Cnr1 KO mice differed from WT littermates in total distance traveled, and both showed significantly less rearing activity than did their WT controls; by contrast, the Cnr1 KO mice spent significantly less time than WT 

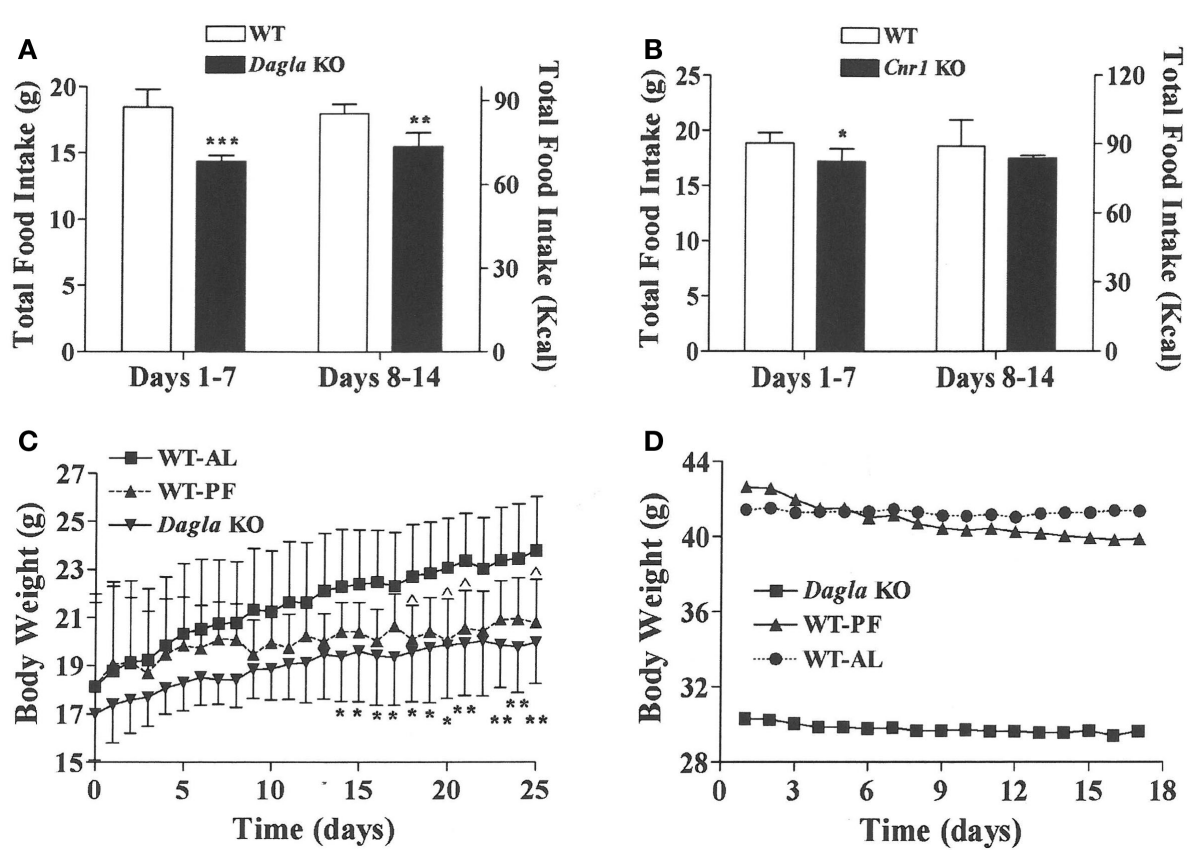

FIGURE 4 | Decreased food intake by Dagla and Cnr1 KO mice at weaning. (A) Intake of HFD by Dagla male mice (three mice/cage, five cages/genotype). (B) Intake of HFD by Cnr1 male mice (two to three mice/cage, five cages/genotype). For (A,B), KO mice different from WT mice, ${ }^{\star} P<0.05,{ }^{\star *} P<0.01,{ }^{\star * \star} P<0.001$. (C) Body weights of ad lib-fed Dagla KO mice, ad lib-fed WT littermate mice (WT-AL), and WT littermate mice that were pair-fed to the Dagla KO mice (WT-PF). Mice were

individually housed weanling female littermates fed LFD; seven mice/ group. KO mice different from WT-AL mice, ${ }^{\star} P<0.05,{ }^{\star \star} P<0.01$; WT-PF mice different from WT-AL mice, $\wedge P<0.05$. (D) Body weights of ad lib-fed Dagla KO mice, ad lib-fed WT littermate mice (WT-AL), and WT littermate mice that were pair-fed to the Dagla KO mice (WT-PF). All mice were individually housed 27-week-old male littermates fed HFD; seven mice/group.

littermates in the center of the open field, whereas Dagla KO and WT littermates were not different for this parameter. This last finding was revisited in the platform test, which provides a more specific measure of anxiety-related behavior (38); Dagla KO mice spent significantly more time than WT mice in the lighted area, and a much smaller cohort of Cnr1 KO and WT mice did not differ significantly for this parameter. Finally, both Dagla and Cnr1 KO mice buried significantly fewer marbles during the marble burying test, and both took significantly longer than their WT littermate controls to respond to a thermal stimulus during the hot plate test. For all tests except the marble burying in Dagla KO mice, and the forced swim and platform tests in Cnrl KO mice, the findings in Table 3 were confirmed with at least one additional independent cohort of mice (data not shown).

Long-term survival was significantly decreased in Dagla KO mice (Figure 7). Despite this impaired survival, aging Dagla KO mice appeared healthy. In a cohort of 12 Dagla KO mice that were at least 1 year of age at necropsy, no pathological changes were noted in brain, heart, or other tissues examined that could explain the decreased survival of these mice (data not shown). On three separate occasions, Dagla KO mice undergoing QMR were observed to have spontaneous seizure activity and none of these mice survived the seizure episode, suggesting that the decreased survival was related to an underlying neurological abnormality which was not evident during histopathologic analysis of brain tissue.

\section{Discussion}

Our Dagla and Cnr1 KO mice share the same lean phenotype when raised on either chow or HFD. In fact, the similarity of their lean phenotypes was remarkable, with body fat 47 and $45 \%$ lower in Dagla and Cnr1 KO mice, respectively, relative to WT littermates. By contrast, Daglb and Napepld KO mice had normal body fat stores. The lean phenotype of our Cnrl KO mice confirms published data $(17,20,30)$. By contrast, body fat data have not been reported for Dagla or Daglb KO mice, although one study did report that BW was significantly decreased in Dagla KO mice and slightly decreased in Daglb KO mice (32). The absence of a body composition phenotype in Napepld KO mice is consistent with recent data indicating that this enzyme is not required for maintenance of normal CNS AEA levels (9). We also found that Dagla and Cnr1 KO mice are hypophagic, consistent with past studies showing decreased feeding behavior in Cnrl KO mice (17, $18,20)$. In our studies, decreased food intake was demonstrated in weanling Dagla and Cnr1 KO mice at a time when their lean phenotype was developing. In addition, a pair-feeding study performed in weanling Dagla KO mice showed that hypophagia was the mechanism behind their lean phenotype, a result identical to that reported for a pair-feeding study of weanling Cnr $1 \mathrm{KO}$ mice (17). The important role of hypophagia in development of the lean phenotype in Dagla and Cnr1 KO mice suggests that the lean phenotype results primarily from loss of Dagla-generated 2-AG 

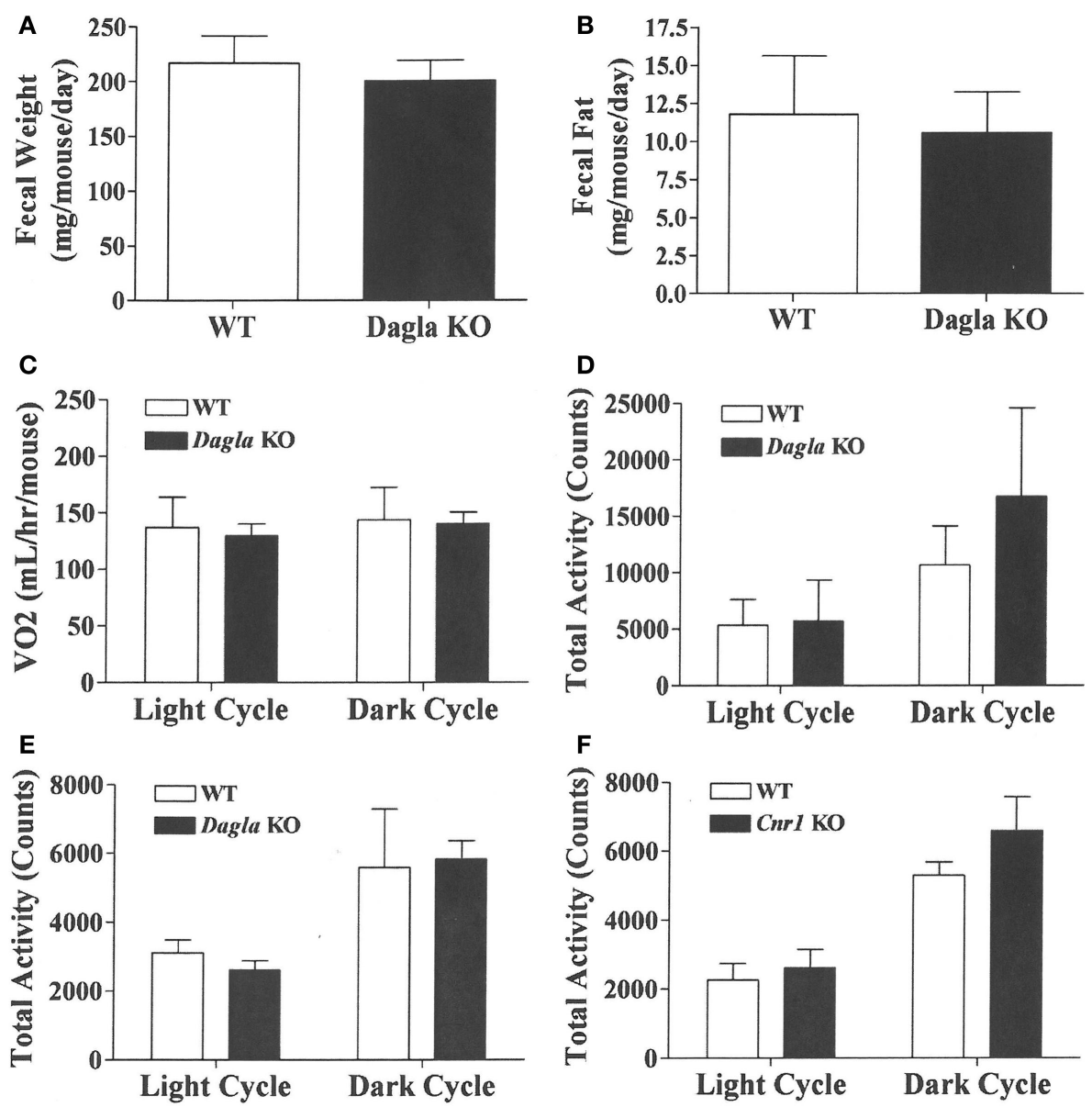

FIGURE 5 | Fecal weight, fecal fat and $\mathrm{VO}_{2}$ of Dagla $\mathrm{KO}$ mice, and activity levels of Dagla and Cnr1 KO mice. Fecal weight (A) and fecal fat (B) from HFD-fed, 8-week-old group-housed male Dagla KO (four cages) and WT littermate (five cages) mice; mice were housed three per cage. $\mathrm{VO}_{2}(\mathbf{C})$ and total activity (D) levels of HFD-fed, 45-week-old female Dagla KO mice $(N=6)$ and their WT littermates $(N=8)$ measured in Oxymax chambers over $24 \mathrm{~h}$ as

described in the Section "Materials and Methods." (E) Total activity levels of HFD-fed, 30-week-old male Dagla KO mice $(N=9)$ and their WT littermates $(N=7)$, and $(\mathbf{F})$ activity levels of HFD-fed, 30-week-old male Cnr1 KO mice $(N=5)$ and their WT littermates $(N=6)$, measured over 3 weeks in the ER-4000 physiological measurement system as described in the Section "Materials and Methods."

signaling through Cnr1 expressed by CNS rather than by peripheral tissues. This hypothesis is consistent with the observations that: (1) Cnr1 and Dagla are most highly expressed in the CNS, (2) brain 2-AG levels are much lower in Dagla KO mice compared to Daglb KO mice, and (3) removal of Cnrl from neurons known to regulate energy balance, but not from non-neuronal peripheral tissues, is all that is required to reproduce the lean phenotype observed in global Cnr1 KO mice [(32, 33, 42, 43); our unpublished observations]. Interestingly, hypophagia was not as pronounced in older Dagla KO mice, and in fact pair-feeding of WT mice to Dagla KO mice was not associated with marked loss of BW relative to ad lib-fed WT littermates, a finding that exactly reproduced results reported for pair-feeding studies using older Cnr1 KO mice (17). Such results may simply reflect increased food intake as an adaptation to maintain already depleted body fat stores and LBM in adult Dagla and Cnr1 KO mice, or they could suggest that food intake-independent mechanisms were operative in adult $\mathrm{KO}$ mice. However, activity was not increased in either our adult Dagla or Cnr1 KO mice in three independent assays and there was no evidence of malabsorption in our Dagla $\mathrm{KO}$ mice. Also, $\mathrm{VO}_{2}$ was not increased in our Dagla KO mice or in Cnr1 KO mice studied by others (17); however, the error inherent in the indirect calorimetry method and the ability of Cnr1 inverse agonists to increase energy expenditure in rodents and humans $(44,45)$ suggest that additional studies are needed to determine if increased energy expenditure contributes to the lean phenotype of older Dagla KO mice.

A number of metabolic parameters were studied in Dagla and Cnr1 KO mice. Neither HFD-fed Dagla nor Cnr1 KO mice showed consistent improvements in fasting blood glucose levels or glucose excursions during OGTTs, but both KOs had significantly lower insulin levels during a fast and $30 \mathrm{~min}$ after glucose challenge, along with lower triglyceride (TG) and total cholesterol levels. These results are similar to $\mathrm{Cnr} 1 \mathrm{KO}$ mouse data published by others (20, 42, 43, 46). Dagla KO mice-fed western diet also showed a decrease in hepatic steatosis, which mirrored their decrease in total body fat. Past studies initially suggested that hepatic Cnr1 deficiency 

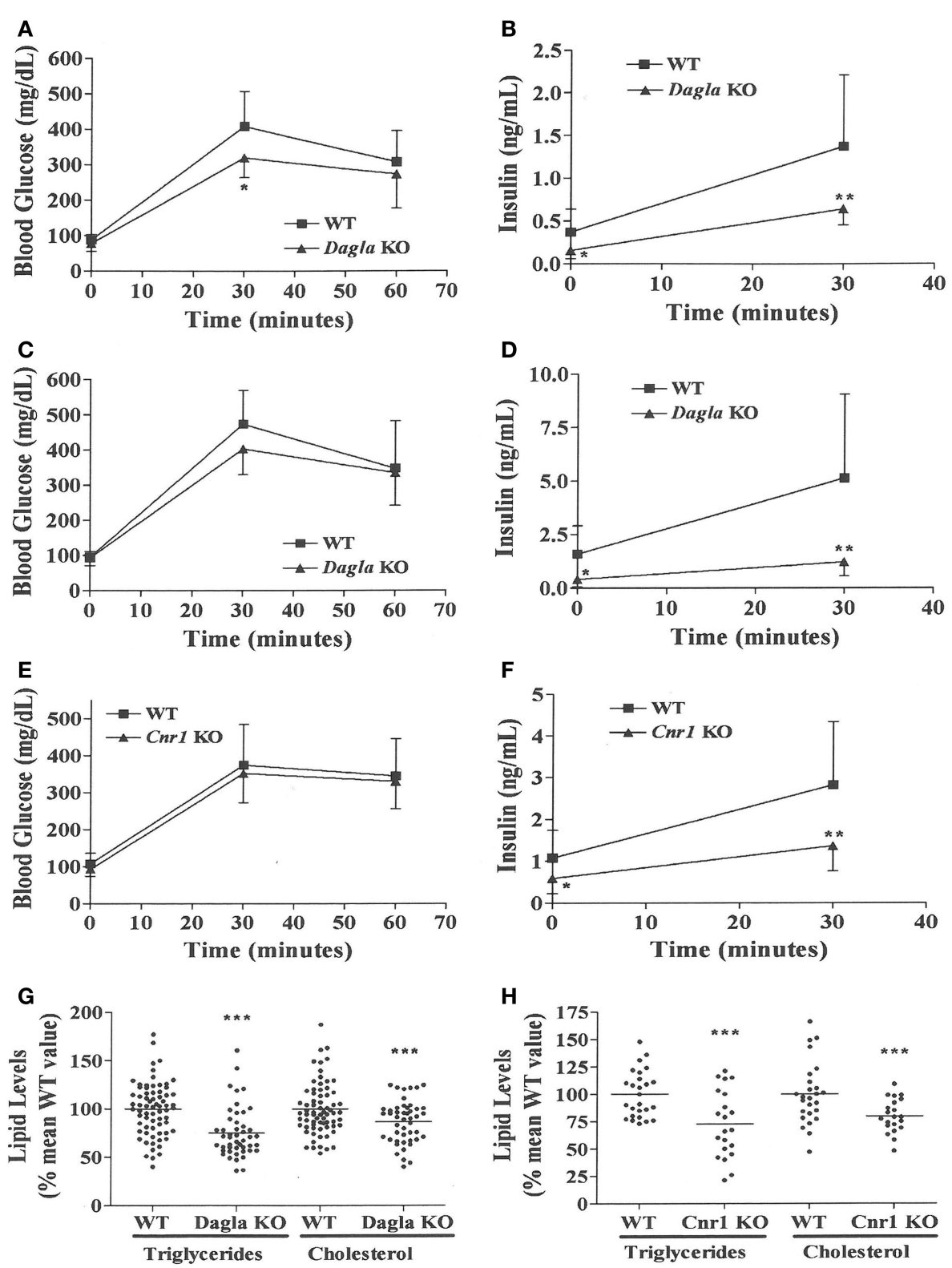

FIGURE 6 | Improved OGTT and fasting serum lipid measurements in Dagla and Cnr1 KO mice. (A) Glucose excursions, and (B) 0 and 30 min insulin levels, from an OGTT performed on HFD-fed male Dagla KO mice $(N=12)$ and their WT littermates $(N=14)$ at 16 weeks of age. (C) Glucose excursions, and (D) 0 and 30 min insulin levels, from an OGTT performed on and independent cohort of HFD-fed male Dagla KO mice $(N=10)$ and their WT littermates $(N=6)$ at 18 weeks of age. (E) Glucose excursions, and (F) 0 and

30 min insulin levels, from an OGTT performed on HFD-fed male Cnr1 KO mice $(N=14)$ and their WT littermates $(N=15)$ at 16 weeks of age. For $(\mathbf{A}-\mathbf{F})$ above, KO glucose AUC and insulin levels different from $\mathrm{WT}$, ${ }^{\star} P<0.05$, ${ }^{\star \star} P<0.01$. Normalized fasting serum triglyceride and total cholesterol levels from (G) adult Dagla KO mice $(N=47)$ and their WT littermates $(N=70)$, and (H) adult Cnr1 KO mice $(N=21)$ and their WT littermates $(N=26)$; KO different from $\mathrm{WT},{ }^{* \star *} P<0.001$.

alone prevented the HFD-induced development of hepatic steatosis, insulin resistance, and dyslipidemia, whereas extra-hepatic Cnrl deficiency was required to prevent HFD-induced obesity (46). Although subsequent studies reported that CNS-specific Cnr1 deficiency alone prevented HFD-induced hepatic steatosis, insulin resistance, and dyslipidemia $(42,43)$, recent data indicate that peripherally restricted $\mathrm{Cnr} 1$ antagonists can indeed prevent this metabolic syndrome (47). Our data suggest that, wherever the
Cnr1 that confers each of these effects is expressed, Dagla must also be expressed to provide the 2-AG that serves as the EC signal.

Mice treated with rimonabant show the same resistance to hepatic steatosis, insulin resistance, dyslipidemia, and obesity as do mice lacking Cnr1 (19, 20, 42, 43, 46, 48) or Dagla (data presented here), suggesting that Dagla inhibitors may achieve the same effects as Cnrl inverse agonists if delivered to the right location. In obese humans with T2D, rimonabant significantly lowered BW, A1C, 
TABLE 2 | Serum lipids, liver function/steatosis, and body fat in Dagla KO, ApoE KO, and Dagla/ApoE DKO mice-fed Western diet.

\begin{tabular}{lcccc}
\hline & WT & Dagla KO & ApoE KO & D/A DKO \\
\hline ALT, U/L & $136 \pm 107(19)$ & $137 \pm 98(13)$ & $124 \pm 94(17)$ & $43 \pm 35(10)$ \\
AST, U/L & $87 \pm 72(19)^{\star \star \star}$ & $83 \pm 23(13)^{\star \star}$ & $176 \pm 85(17)$ & $90 \pm 49(10)^{\star}$ \\
$\mathrm{TG}, \mathrm{mg} / \mathrm{dL}$ & $82 \pm 17(19)^{\star \star \star}$ & $84 \pm 15(13)^{\star \star \star}$ & $308 \pm 153(17)$ & $171 \pm 71(10)^{\star \star}$ \\
$\mathrm{Chol}, \mathrm{mg} / \mathrm{dL}$ & $220 \pm 76(19)^{\star \star \star}$ & $173 \pm 59(13)^{\star \star \star}$ & $1713 \pm 621(17)$ & $823 \pm 759(10)^{\star \star \star}$ \\
Body fat $^{\mathrm{a}}, \mathrm{g}$ & $14.7 \pm 4.2(19)$ & $8.3 \pm 3.7(13)^{\wedge \wedge}$ & $13.4 \pm 5.5(17)$ & $6.7 \pm 4.1(10)$ \\
Liver steatosis $^{\mathrm{b}}$ & $2.9 \pm 1.5(5)$ & $1.3 \pm 1.0(11)^{\wedge \wedge}$ & $2.8 \pm 0.5(7)$ & $1.4 \pm 1.0(7)$ \\
Liver $_{\text {inflammation }}{ }^{\mathrm{C}}$ & $1.2 \pm 1.2(5)$ & $0.8 \pm 0.8(7)$ & $2.0 \pm 0.5(11)$ & $1.6 \pm 0.8(7)$
\end{tabular}

$N$, number of mice; TG, triglyceride; Chol, total cholesterol; D/A DKO, Dagla/ApoE double KO mice. All serum samples obtained from fed female mice at 20-24 weeks of age.

${ }^{a}$ Body fat measured by QMR at 20-24 weeks of age.

biver steatosis score in semi quantitative units (see Materials and Methods); higher value suggests more steatosis.

'Liver inflammation score in semi quantitative units (see Materials and Methods): higher value suggests more inflammation.

Different from WT by two-way ANOVA, $\wedge \wedge P<0.001$. Different from ApoE KO by one-way ANOVA, ${ }^{*} P<0.05,{ }^{* *} P<0.01,{ }^{* *} P<0.001$.

TABLE 3 | Behavioral studies in Dagla and Cnr1 KO mice.

\begin{tabular}{|c|c|c|c|c|}
\hline \multirow[b]{2}{*}{ Test } & \multicolumn{2}{|c|}{ Dagla } & \multicolumn{2}{|c|}{ Cnr1 } \\
\hline & WT & KO & WT & KO \\
\hline \multicolumn{5}{|c|}{ Tail suspension } \\
\hline $\begin{array}{l}\text { Immobility } \\
\text { time, s }\end{array}$ & $104 \pm 40(21)$ & $129 \pm 64(16)$ & $76 \pm 42(24)$ & $94 \pm 56(20)$ \\
\hline \multicolumn{5}{|l|}{ Forced swim } \\
\hline $\begin{array}{l}\text { Immobility } \\
\text { time, s }\end{array}$ & $237 \pm 66(25)$ & $123 \pm 86(17)^{\star \star \star}$ & $168 \pm 77(8)$ & $84 \pm 78(6)$ \\
\hline \multicolumn{5}{|l|}{ Open field } \\
\hline $\begin{array}{l}\text { Total distance, } \\
\mathrm{cm}\end{array}$ & $2244 \pm 783(26)$ & $2138 \pm 766(18)$ & $1724 \pm 917(25)$ & $1265 \pm 855(24)$ \\
\hline $\begin{array}{l}\text { Time in } \\
\text { center, s }\end{array}$ & $313 \pm 117(26)$ & $267 \pm 193(18)$ & $346 \pm 198(25)$ & $147 \pm 108(24)^{\star \star \star *}$ \\
\hline Rearing, $N$ & $51 \pm 25(26)$ & $29 \pm 26(18)^{\star \star}$ & $50 \pm 43(25)$ & $13 \pm 18(24)^{\star \star \star}$ \\
\hline \multicolumn{5}{|l|}{ Platform } \\
\hline $\begin{array}{l}\text { Time in } \\
\text { light, s }\end{array}$ & $75 \pm 68(26)$ & $187 \pm 77(17)^{\star \star \star}$ & $108 \pm 97(8)$ & $70 \pm 100(7)$ \\
\hline \multicolumn{5}{|l|}{ Hot plate } \\
\hline $\begin{array}{l}\text { Latency to } \\
\text { respond, s }\end{array}$ & $10.6 \pm 3.6(26)$ & $15.3 \pm 5.3(18)^{\star \star}$ & $8.6 \pm 3.5$ & $10.9 \pm 3.9(24)^{*}$ \\
\hline \multicolumn{5}{|c|}{ Marble burying } \\
\hline $\begin{array}{l}\text { Marbles } \\
\text { buried, } N\end{array}$ & $13 \pm 7(26)$ & $6 \pm 7(18)^{\star \star}$ & $10 \pm 7(25)$ & $4 \pm 5(24)^{\star \star \star}$ \\
\hline
\end{tabular}

$N$, number of mice; s, seconds. Different from $W T$, ${ }^{*} P<0.05,{ }^{* *} P<0.01,{ }^{* * *} P<0.001$. Note: Cnr1 forced swim and platform tests were analyzed by Student's t-test because only female mice were studied. In all other groups, two-way ANOVA showed no gender $\times$ genotype interaction, so male and female data were combined.

insulin resistance, and serum TGs $(22,49)$, suggesting that Dagla inhibitors will also be effective in these individuals. Of the few Dagla inhibitors studied, the most promising data are for O-7460, a small molecule that lowered food intake in a dose-dependent manner during the $14 \mathrm{~h}$ after a single intraperitoneal injection; the highest dose was associated with slight but significant decreases in BW and hypothalamic 2-AG levels (50). Unfortunately, hypophagia is a common sign of off-target toxicity for many compounds. For this reason, developers of the Cnr1 inverse agonists, rimonabant and taranabant, demonstrated that their compounds lowered food

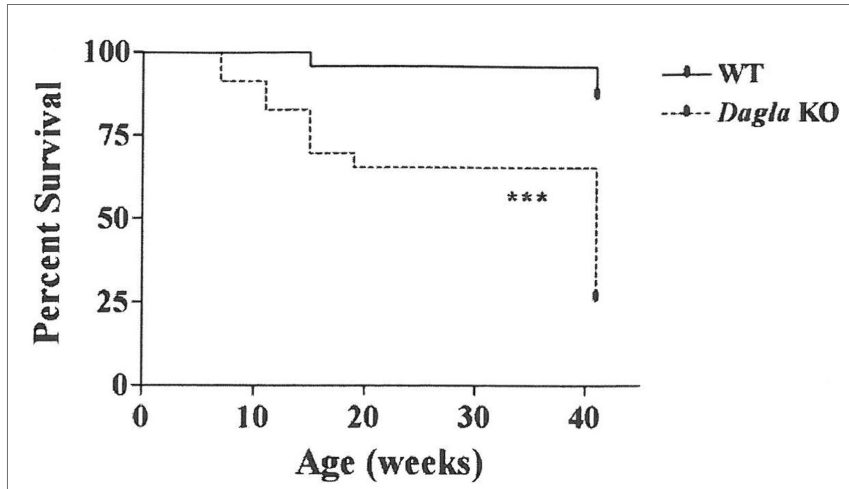

FIGURE 7 | Decreased survival of Dagla KO mice. Survival curves of combined male and female Dagla KO mice and their WT littermates from weaning through 41 weeks of age. KO different from WT, ${ }^{\star \star \star} P<0.001$.

intake in WT but not Cnr1 KO mice $(19,51)$. Dagla inhibitors should also be tested in Dagla KO mice early in preclinical development to confirm that their effects on food intake are truly on-target.

The EC system plays an important role in regulating emotional behavior (26). Although the Cnr1 inverse agonist rimonabant was an effective anti-obesity agent, it was often associated with affective disturbances such as anxiety and depression that made it unsuitable for routine use $(22,24,25)$. The value of Dagla as an anti-obesity target would be enhanced if the favorable metabolic phenotype shared by Dagla and Cnr1 KO mice was not linked to the undesirable neuropsychiatric effects associated with rimonabant. For this reason, we chose to evaluate Dagla and Cnr1 KO mice in a series of tests designed to evaluate anxiety, depression, and other behaviors. Interestingly, published studies that used these behavioral tests to evaluate Cnr1 KO mice, or WT mice treated with compounds that modulate Cnr1 signaling, reported results that were often inconsistent with each other and with data we collected on our Cnr1 KO mice $(39,40,52-61)$. This suggested that the value in our behavioral screen would come from directly comparing the behavioral phenotypes of Dagla and Cnrl KO mice obtained in our laboratory. We found that Dagla and Cnrl KO mice differed only in the open-field time in center and the platform tests, two related tests that use the same open-field chamber; here Dagla KO mice exhibited a more anxiolytic behavior. Dagla and Cnr1 KO mice showed similar behaviors in the hot plate, marble burying, open-field rearing, forced swim, open-field distance traveled, and tail suspension tests; for the first four of these tests, the behavior of KO mice from both lines appeared different from WT. The fact that both Dagla and Cnr1 KO mice responded similarly in most of the tests suggests that the 2-AG synthesized by Dagla is mediating not only effects on pathways regulating food intake and various metabolic parameters but also effects on pathways that influence important neuropsychiatric behaviors. Our studies were limited by the fact that we only employed a few acute assays to assess depression and anxiety (62). In addition, the open-field time in center and platform tests suggest the possibility that the two KO lines may differ in anxiety-related behavior, with Dagla $\mathrm{KO}$ mice exhibiting a more anxiolytic response; this is a potentially important finding, because it raises the possibility that Dagla KO mice do not share an undesirable behavioral phenotype present 
in Cnr1 KO mice. Additional studies are therefore needed; if they ultimately confirm our overall impression that Dagla and Cnr1 KO mice share behavioral phenotypes, the response to Dagla inhibitors may well be similar to the response to Cnrl antagonists and inverse agonists for both metabolic and neuropsychiatric effects. Finally, we observed seizure activity followed by death in three Dagla KO mice; this may explain the decreased survival of our Dagla KO line, which occurs despite a lack of histopathologic findings. Although we did not assess survival of our Cnr1 KO mice, others reported increased seizure activity and decreased survival without an obvious cause of death in Cnrl KO mice (21). These shared findings provide further evidence for a close interaction between Dagla and Cnr1 in the normal regulation of multiple neurologic pathways.

Our high-throughput phenotypic screen correctly identified the lean phenotypes of Cnr1 and Dagla KO mice, just as it correctly identified the body fat phenotype of many KO lines in past studies; some of these KOs share their phenotype with humans having inactivating mutations in the same gene $(30,35,63)$. Our screen has also identified genes that play a key role in regulating bone mass (31). Continued mining of our $\mathrm{KO}$ data, and $\mathrm{KO}$ data generated by the International Mouse Knockout Consortium, should identify genes that, when mutated, (1) result in specific diseases and (2) can be targeted to develop therapeutics for obesity, diabetes, osteoporosis, and other indications.

In summary, our data suggest that, in pathways where ECs signal through Cnr1 to regulate food intake, certain other behaviors and also other aspects of the metabolic phenotype observed in Cnr1 KO mice, Dagla alone provides the $2-\mathrm{AG}$ that serves as the EC signal. Based on these data, small molecule Dagla inhibitors with a pharmacokinetic profile similar to that of Cnrl inverse agonists are likely to mirror the ability of these inverse agonists to decrease food intake, BW, TGs, and insulin resistance while improving glycemic control in obese patients with diabetes. Whether Dagla inhibitors

\section{References}

1. Wang YC, McPherson K, Marsh T, Gortmaker SL, Brown M. Health and economic burden of the projected obesity trends in the USA and the UK. Lancet (2011) 378:815-25. doi:10.1016/S0140-6736(11)60814-3

2. Sherwin R, Jastreboff AM. Year in diabetes 2012: the diabetes tsunami. J Clin Endocrinol Metab (2012) 97:4293-301. doi:10.1210/jc.2012-3487

3. Kim GW, Lin JE, Blomain ES, Waldman SA. Antiobesity pharmacotherapy: new drugs and emerging targets. Clin Pharmacol Ther (2014) 95:53-66. doi:10.1038/ clpt.2013.204

4. Silvestri C, Di Marzo V. The endocannabinoid system in energy homeostasis and the etiopathology of metabolic disorders. Cell Metab (2013) 17:475-90. doi:10.1016/j.cmet.2013.03.001

5. Howlett AC, Barth F, Bonner TI, Cabral G, Casellas P, Devane WA, et al. International union of pharmacology. XXVII. classification of cannabinoid receptors. Pharmacol Rev (2002) 54:161-202. doi:10.1124/pr.54.2.161

6. Bisogno T, Howell F, Williams G, Minassi A, Cascio MG, Ligresti A, et al. Cloning of the first sn1-DAG lipases points to the spatial and temporal regulation of endocannabinoid signaling in the brain. JCell Biol (2003) 163:463-8. doi:10.1083/ jcb.200305129

7. Di Marzo V. Endocannabinoids: synthesis and degradation. Rev Physiol Biochem Pharmacol (2008) 160:1-24. doi:10.1007/112_0505

8. Muccioli GG. Endocannabinoid biosynthesis and inactivation, from simple to complex. Drug Discov Today (2010) 15:474-83. doi:10.1016/j. drudis.2010.03.007

9. Simon GM, Cravatt BF. Characterization of mice lacking candidate $N$-acyl ethanolamine biosynthetic enzymes provides evidence for multiple pathways that will also be associated with undesirable neuropsychiatric events similar to those observed with use of Cnr1 inverse agonists, which must be considered possible based on data presented here, can only be answered with human clinical trials.

\section{Author Contributions}

DP, KS, TL, ZD, UD, and BZ made substantial contributions to the conception or design of the work. DP, KS, UD, JG, NW, DD, $\mathrm{RR}, \mathrm{PV}, \mathrm{GH}, \mathrm{RB}$, and $\mathrm{ZD}$ made substantial contributions to the acquisition, analysis, or interpretation of data for the work. DP, $\mathrm{ZD}$, and UD participated in drafting the work. JG, NW, DD, KS, TL, RR, PV, GH, RB, and BZ participated in revising it critically for important intellectual content. All authors provided final approval of the version to be published. All authors agree to be accountable for all aspects of the work in ensuring that questions related to the accuracy or integrity of any part of the work are appropriately investigated and resolved.

\section{Acknowledgments}

The authors wish to thank Kristi Boehm, MS, ELS for her help in preparing the figures and tables. This work was presented in part at the 96th Annual Meeting of the Endocrine Society, June 21-24, 2014 in Chicago, IL, USA, and at the 97th Annual Meeting of the Endocrine Society, March 5-8, 2015 in San Diego, CA, USA.

\section{Supplementary Material}

The Supplementary Material for this article can be found online at http://www.frontiersin.org/Journal/10.3389/fendo.2015.00086/ abstract

contribute to endocannabinoid production in vivo. Mol Biosyst (2010) 6:1411-8. doi:10.1039/c000237b

10. Pertwee RG, Ross RA. Cannabinoid receptors and their ligands. Prostaglandins Leukot Essent Fatty Acids (2002) 66:101-21. doi:10.1054/plef.2001.0341

11. Okamoto Y, Morishita J, Tsuboi K, Tonai T, Ueda N. Molecular characterization of a phospholipase D generating anandamide and its congeners. J Biol Chem (2004) 279:5298-305. doi:10.1074/jbc.M306642200

12. Ohno-Shosaku T, Kano M. Endocannabinoid-mediated retrograde modulation of synaptic transmission. Curr Opin Neurobiol (2014) 29:1-8. doi:10.1016/j. conb.2014.03.017

13. Colombo G, Agabio R, Diaz G, Lobina C, Reali R, Gessa GL. Appetite suppression and weight loss after the cannabinoid antagonist SR 141716. Life Sci (1998) 63:PL113-7. doi:10.1016/S0024-3205(98)00322-1

14. Williams CM, Kirkham TC. Anandamide induces overeating: mediation by central cannabinoid (CB1) receptors. Psychopharmacology (Berl) (1999) 143:315-7. doi:10.1007/s002130050953

15. Jamshidi N, Taylor DA. Anandamide administration into the ventromedial hypothalamus stimulates appetite in rats. Br J Pharmacol (2001) 134:1151-4. doi:10.1038/sj.bjp.0704379

16. Kirkham TC, Williams CM, Fezza F, Di Marzo V. Endocannabinoid levels in rat limbic forebrain and hypothalamus in relation to fasting, feeding and satiation: stimulation of eating by 2-arachidonoyl glycerol. Br J Pharmacol (2002) 136:550-7. doi:10.1038/sj.bjp.0704767

17. Cota D, Marsicano G, Tschöp M, Grübler Y, Flachskamm C, Schubert M, et al. The endogenous cannabinoid system affects energy balance via central orexigenic drive and peripheral lipogenesis. J Clin Invest (2003) 112:423-31. doi:10.1172/ JCI17725 
18. Di Marzo V, Goparaju SK, Wang L, Liu J, Bátkai S, Járai Z, et al. Leptin-regulated endocannabinoids are involved in maintaining food intake. Nature (2001) 410:822-5. doi:10.1038/35071088

19. Ravinet Trillou C, Arnone M, Delgorge C, Gonalons N, Keane P, Maffrand JP, et al. Anti-obesity effect of SR141716, a CB1 receptor antagonist, in diet-induced obese mice. Am J Physiol Regul Integr Comp Physiol (2003) 284:R345-53. doi:10.1152/ ajpregu.00545.2002

20. Ravinet Trillou C, Delgorge C, Menet C, Arnone M, Soubrié P. CB1 cannabinoid receptor knockout in mice leads to leanness, resistance to diet-induced obesity and enhanced leptin sensitivity. Int J Obes Relat Metab Disord (2004) 28:640-8. doi:10.1038/sj.ijo.0802583

21. Zimmer A, Zimmer AM, Hohmann AG, Herkenham M, Bonner TI. Increased mortality, hypoactivity, and hypoalgesia in cannabinoid CB1 receptor knockout mice. Proc Natl Acad Sci U S A (1999) 96:5780-5. doi:10.1073/pnas.96.10.5780

22. Van Gaal L, Pi-Sunyer X, Després JP, McCarthy C, Scheen A. Efficacy and safety of rimonabant for improvement of multiple cardiometabolic risk factors in overweight/obese patients: pooled 1-year data from the rimonabant in obesity (RIO) program. Diabetes Care (2008) 31(Suppl 2):S229-40. doi:10.2337/dc08-s258

23. Leite CE, Mocelin CA, Petersen GO, Leal MB, Thiesen FV. Rimonabant: an antagonist drug of the endocannabinoid system for the treatment of obesity. Pharmacol Rep (2009) 61:217-24. doi:10.1016/S1734-1140(09)70025-8

24. Martins CJ, Genelhu V, Di Marzo V, Francischetti EA. The endocannabinoid system - back to the scene of cardiometabolic risk factors control. Horm Metab Res (2014) 46:529-36. doi:10.1055/s-0034-1375653

25. Moreira FA, Crippa JA. The psychiatric side-effects of rimonabant. Rev Bras Psiquiatr (2009) 31:145-53. doi:10.1590/S1516-44462009000200012

26. Valverde O, Rorrens M. CB1 receptor-deficient mice as a model for depression. Neuroscience (2012) 204:193-206. doi:10.1016/j.neuroscience.2011.09.031

27. Beltrandelrio H, Kern F, Lanthorn T, Oravecz T, Piggott J, Powell D, et al. Saturation screening of the druggable mammalian genome. In: Carroll PM, Fitzgerald K, editors. Model Organisms in Drug Discovery. Chichester: Wiley \& Sons (2003). p. $251-78$.

28. Zambrowicz BP, Sands AT. Knockouts model the 100 best-selling drugs-will they model the next 100? Nat Rev Drug Discov (2003) 2:38-51. doi:10.1038/nrd987

29. Zambrowicz BP, Abuin A, Ramirez-Solis R, Richter LJ, Piggott J, BeltrandelRio H, et al. Wnk1 kinase deficiency lowers blood pressure in mice: a gene-trap screen to identify potential targets for therapeutic intervention. Proc Natl Acad Sci U S A (2003) 100:14109-14. doi:10.1073/pnas.2336103100

30. Brommage R, Desai U, Revelli JP, Donoviel DB, Fontenot GK, Dacosta CM, et al. High-throughput screening of mouse knockout lines identifies true lean and obese phenotypes. Obesity (2008) 16:2362-7. doi:10.1038/oby.2008.361

31. Brommage R, Liu J, Hansen G, Kirkpatrick LL, Potter DG, Sands AT, et al. Highthroughput screening of mouse gene knockouts identifies established and novel skeletal phenotypes. Bone Res (2014) 2:article14034. doi:10.1038/boneres.2014.34

32. Gao Y, Vasilyev DV, Goncalves MB, Howell FV, Hobbs C, Reisenberg M, et al. Loss of retrograde endocannabinoid signaling and reduced adult neurogenesis in diacylglycerol lipase knock-out mice. J Neurosci (2010) 30:2017-24. doi:10.1523/ JNEUROSCI.5693-09.2010

33. Yoshino H, Miyamae T, Hansen G, Zambrowicz B, Flynn M, Pedicord D, et al. Postsynaptic diacylglycerol lipase mediates retrograde endocannabinoid suppression of inhibition in mouse prefrontal cortex. J Physiol (2011) 589:4857-84. doi:10.1113/jphysiol.2011.212225

34. Powell DR, DaCosta CM, Gay J, Ding ZM, Smith M, Greer J, et al. Improved glycemic control in mice lacking Sglt1 and Sglt2. Am J Physiol Endocrinol Metab (2013) 304:E117-30. doi:10.1152/ajpendo.00439.2012

35. Revelli JP, Smith D, Allen J, Jeter-Jones S, Shadoan MK, Desai U, et al. Profound obesity secondary to hyperphagia in mice lacking kinase suppressor of ras 2 . Obesity (2011) 19:1010-8. doi:10.1038/oby.2010.282

36. Kleiner DE, Brunt EM, Van Natta M, Behling C, Contos MJ, Cummings OW, et al. Design and validation of a histological scoring system for nonalcoholic fatty liver disease. Hepatology (2005) 41:1313-21. doi:10.1002/hep.20701

37. Cryan JF, Mombereau C, Vassout A. The tail suspension test as a model for assessing antidepressant activity: review of pharmacological and genetic studies in mice. Neurosci Biobehav Rev (2005) 29:571-625. doi:10.1016/j. neubiorev.2005.03.009

38. Pogorelov VM, Lanthorn TH, Savelieva KV. Use of a platform in an automated open-field to enhance assessment of anxiety-like behaviors in mice. J Neurosci Methods (2007) 162:222-8. doi:10.1016/j.jneumeth.2007.01.015
39. Valverde O, Karsak M, Zimmer A. Analysis of the endocannabinoid system by using CB1 cannabinoid receptor knockout mice. Handb Exp Pharmacol (2005) 168:117-45. doi:10.1007/3-540-26573-2_4

40. Gomes FV, Casarotto PC, Resstel LB, Guimarães FS. Facilitation of CB1 receptor-mediated neurotransmission decreases marble burying behavior in mice. Prog Neuropsychopharmacol Biol Psychiatry (2011) 35:434-8 doi:10.1016/j. pnpbp.2010.11.027

41. Savelieva KV, Zhao S, Pogorelov VM, Rajan I, Yang Q, Cullinan E, et al. Genetic disruption of both tryptophan hydroxylase genes dramatically reduces serotonin and affects behavior in models sensitive to antidepressants. PLoS One (2008) 10:e3301. doi:10.1371/journal.pone.0003301

42. Quarta C, Bellocchio L, Mancini G, Mazza R, Cervino C, Braulke LJ, et al. CB(1) signaling in forebrain and sympathetic neurons is a key determinant of endocannabinoid actions on energy balance. Cell Metab (2010) 11:273-85. doi:10.1016/j. cmet.2010.02.015

43. Pang Z, Wu NN, Zhao W, Chain DC, Schaffer E, Zhang X, et al. The central cannabinoid CB1 receptor is required for diet-induced obesity and rimonabant's antiobesity effects in mice. Obesity (2011) 19:1923-34. doi:10.1038/oby.2011.250

44. Liu YL, Connoley IP, Wilson CA, Stock MJ. Effects of the cannabinoid CB1 receptor antagonist SR141716 on oxygen consumption and soleus muscle glucose uptake in Lep(ob)/Lep(ob) mice. Int JObes (Lond) (2005) 29:183-7. doi:10.1038/ sj.ijo.0802847

45. Addy C, Wright H, Van Laere K, Gantz I, Erondu N, Musser BJ, et al. The acyclic CB1R inverse agonist taranabant mediates weight loss by increasing energy expenditure and decreasing caloric intake. Cell Metab (2008) 7:68-78. doi:10.1016/j. cmet.2007.11.012

46. Osei-Hyiaman D, Liu J, Zhou L, Godlewski G, Harvey-White J, Jeong WI, et al. Hepatic CB1 receptor is required for development of diet-induced steatosis, dyslipidemia, and insulin and leptin resistance in mice. J Clin Invest (2008) 118:3160-9. doi:10.1172/JCI34827

47. Pacher P, Kunos G. Modulating the endocannabinoid system in human health and disease - successes and failures. FEBS J (2013) 280:1918-43. doi:10.1111/ febs. 12260

48. Watanabe T, Kubota N, Ohsugi M, Kubota T, Takamoto I, Iwabu M, et al. Rimonabant ameliorates insulin resistance via both adiponectin-dependent and adiponectin-independent pathways. JBiol Chem (2009) 284:1803-12. doi:10.1074/ jbc.M807120200

49. Hollander PA, Amod A, Litwak LE, Chaudhari U, ARPEGGIO Study Group. Effect of rimonabant on glycemic control in insulin-treated type 2 diabetes: the ARPEGGIO trial. Diabetes Care (2010) 33:605-7. doi:10.2337/dc09-0455

50. Bisogno T, Mahadevan A, Coccurello R, Chang JW, Allarà M, Chen Y, et al. A novel fluorophosphonate inhibitor of the biosynthesis of the endocannabinoid 2-arachidonoylglycerol with potential anti-obesity effects. Br J Pharmacol (2013) 169:784-93. doi:10.1111/bph.12013

51. Fong TM, Guan XM, Marsh DJ, Shen CP, Stribling DS, Rosko KM, et al. Antiobesity efficacy of a novel cannabinoid-1 receptor inverse agonist, $N$-[(1S,2S)-3-(4-chlorophenyl)-2-(3-cyanophenyl)-1-methylpropyl]-2-methyl2-[[5-(trifluoromethyl)pyridin-2-yl] oxy]propanamide (MK-0364), in rodents. J Pharmacol Exp Ther (2007) 321:1013-22. doi:10.1124/jpet.106.118737

52. Richardson JD, Aanonsen L, Hargreaves KM. Hypoactivity of the spinal cannabinoid system results in NMDA-dependent hyperalgesia. J Neurosci (1998) 18:451-7.

53. Calignano A, La Rana G, Giuffrida A, Piomelli D. Control of pain initiation by endogenous cannabinoids. Nature (1998) 394:277-81. doi:10.1038/28393

54. Shearman LP, Rosko KM, Fleischer R, Wang J, Xu S, Tong XS, et al. Antidepressantlike and anorectic effects of the cannabinoid CB1 receptor inverse agonist AM251 in mice. Behav Pharmacol(2003) 14:573-82. doi:10.1097/00008877-200312000-00001

55. Tzavara ET, Davis RJ, Perry KW, Li X, Salhoff C, Bymaster FP. The CB1 receptor antagonist SR141716A selectively increases monoaminergic neurotransmission in the medial prefrontal cortex: implications for therapeutic actions. BrJ Pharmacol (2003) 138:544-53. doi:10.1038/sj.bjp.0705100

56. Fride E, Suris R, Weidenfeld J, Mechoulam R. Differential response to acute and repeated stress in cannabinoid CB1 receptor knockout newborn and adult mice. Behav Pharmacol (2005) 16:431-40. doi:10.1097/00008877-200509000-00016

57. Mato S, Aso E, Castro E, Martín M, Valverde O, Maldonado R, et al. CB1 knockout mice display impaired functionality of 5-HT1A and 5-HT2A/C receptors. $J$ Neurochem (2007) 103:2111-20. doi:10.1111/j.1471-4159.2007.04961.x

58. Thiemann G, Watt CA, Ledent C, Molleman A, Hasenöhrl RU. Modulation of anxiety by acute blockade and genetic deletion of the $\mathrm{CB}(1)$ cannabinoid receptor 
in mice together with biogenic amine changes in the forebrain. Behav Brain Res (2009) 200:60-7. doi:10.1016/j.bbr.2008.12.035

59. Dubreucq S, Koehl M, Abrous DN, Marsicano G, Chaouloff F. CB1 receptor deficiency decreases wheel-running activity: consequences on emotional behaviours and hippocampal neurogenesis. Exp Neurol (2010) 224:106-13. doi:10.1016/j. expneurol.2010.01.017

60. El-Alfy AT, Ivey K, Robinson K, Ahmed S, Radwan M, Slade D, etal. Antidepressantlike effect of delta9-tetrahydrocannabinol and other cannabinoids isolated from Cannabis sativa L. Pharmacol Biochem Behav (2010) 95:434-42. doi:10.1016/j. pbb.2010.03.004

61. Hayase T. Depression-related anhedonic behaviors caused by immobilization stress: a comparison with nicotine-induced depression-like behavioral alterations and effects of nicotine and/or "antidepressant" drugs. J Toxicol Sci (2011) 36:31-41. doi:10.2131/jts.36.31

62. Pollak DD, Rey CE, Monje FJ. Rodent models in depression research: classical strategies and new directions. Ann Med (2010) 42:252-64. doi:10.3109/07853891003769957
63. Pearce LR, Atanassova N, Banton MC, Bottomley B, van der Klaauw A, Revelli J-P, et al. KSR2 mutations are associated with obesity, insulin resistance and impaired cellular fuel oxidation. Cell (2013) 155:765-77. doi:10.1016/j. cell.2013.09.058

Conflict of Interest Statement: All authors were employed by Lexicon Pharmaceuticals, Inc. at the time these studies were performed, and received compensation in the form of salary and stock options.

Copyright (C) 2015 Powell, Gay, Wilganowski, Doree, Savelieva, Lanthorn, Read, Vogel, Hansen, Brommage, Ding, Desai and Zambrowicz. This is an open-access article distributed under the terms of the Creative Commons Attribution License (CC BY). The use, distribution or reproduction in other forums is permitted, provided the original author(s) or licensor are credited and that the original publication in this journal is cited, in accordance with accepted academic practice. No use, distribution or reproduction is permitted which does not comply with these terms. 